\title{
Communication of Ergonomics in building and construction
}

\author{
Viveca Wiberg a \\ ${ }^{a}$ Swedish Work Environment Authority (SWEA)
}

\begin{abstract}
For the coming years SWEA is planning for communication and information actions. One of the sectors concerned is the building and construction industry. Focus of the information is to avoid accidents and injuries, and how companies by themselves can prevent risks. The objective of the information is to increase awareness among all stakeholders in order to secure that they are willing and able to reduce risks for workers. At the conference two brochures will be presented. They are designed to provide information and knowledge about specific risks of occupational accidents and occupational diseases which occur frequently during construction work and how they can be prevented. They are directed to all those who are involved in the construction process at different stages and who are subject to SWEAs rules and regulations. New identified risk groups are e.g. students, apprentices, self-employed, and foreign workers temporarily working in Sweden. We also see that work is still being carried out in narrow installation spaces during erection stage of buildings because the people responsible for the drawings do not take notice of the need for sufficient space to do the work. SWEA experienced that it is difficult to reach all the groups concerned with the message about how to avoid injuries and unnecessary musculoskeletal disorders.
\end{abstract}

Keywords: building and construction, communication, risks, training, ergonomics

\section{Introduction}

The working environment in Sweden is considered good when compared internationally on work accidents and occupational diseases. Over the past five years 68 people have died in construction work and the last year, the fatal accidents have increased again in the construction industry. During the years 2008-2010 five deaths occurred among employees and self-employed in foreign construction companies, with construction contracts in Sweden. Also in 2008 an apprentice was killed during his training period.

In addition to fatal accidents there are numerous other accidents in the industry, such as falls from heights, lost control of hand tools or accident during physical overload (heavy lifting), and these lead to anything from no sick leave to a few days or several weeks of sick leave. In one study (Work related complaints in 2010) about $5.4 \%$ of construction workers said that they had trouble in the past 12 months as a result of occupational accident with sick leave. $46 \%$ of accidents had caused the absence of more than two weeks. (Short work injury facts No. 2/2011 Construction).

In the study Work related disorders $201017.5 \%$ of construction workers indicate that they had experienced work-related problems during the past 12 months because they performed work in strenuous postures, $16.3 \%$ when working with heavy manual handling, and $3.3 \%$ in due to stress and mental strain. $65 \%$ of the 299000 employed construction workers have reported heavy lifting and strenuous movements that cause the notification of occupational disease. (Short work injury facts No. 2 / 2011 Construction)

According to the Work Environment Ordinance (2009:1164) the employer has the duty to immediately inform the Authority when an accident or serious incident has occurred, ie, a $\S 2$ notification. All reported construction accidents and serious incidents are not investigated in depth. Also the form that the employer fill out electronically on our 
website does not set requirements for detailed information on events, the type of work equipment used at the time of injury or how many hours that the employee was on duty at the event. To gain more insight into the very serious construction accidents work depth studies were carried on six accidents 2009. The investigations showed that poor knowledge and experience, lack of clarity in the allocation of responsibilities at the site and poor compliance with regulations were some of the contributing factors to accidents. (Report Depth Studies 2009).

In addition to the factors that emerged from the deep studies our experience say that the time allocated in the planning and design stage is crucial for the prevention of ergonomic hazards in the construction industry. These risks were not included in the studies mentioned above. This means that the physical and tiring job because of high levels of stress at work or if the cause was due to the high work rate and time constraints have not been analyzed as a factor in individual cases.

All accidents and illnesses that workers encounter in the work shall also be notified by the employer to the Social Insurance Office, which sends a copy of the notification to Swedish Work Environment Authority (SWEA). Notifications are coded and is the basis for the work environment surveys carried out in collaboration with the Swedish Bureau of Statistics every second year on work injuries and work-related disorders. The collected information is then used inter alia for SWEA's planning, inspection activities and communications efforts.

\section{Responsibility and knowledge}

A good working environment is not just about preventing illness and accidents for those who are in work, but SWEAs goal is also to proactively ensure that students and apprentices, who are entering the construction industry, have enough knowledge to be prepared for the job requirements from the beginning. SWEA also need to capture those workers leased/ hired temporarily (domestic and international) from temping agencies or by foreign companies. Also the developers and designers who work with the planning and design of construction projects are stakeholders that need more knowledge to enable healthy workplaces for workers during the construction phase. This operator together with the construction safety coordinators lays the foundation for the workers who will work in the completed building. Also the completed buildings and facilities need to serve the craftsmen at temporary operation and maintenance and the buildings shall be easily accessible for people with disabilities. All risks, barriers and deficiencies should be in the drawing stage. A good working environment is an important source for promoting health, productivity and business.

SWEA writes work environment rules that is directly applicable to the industry and has in the last 3-4 decades also produced a variety of brochures in various areas of risk that give information to users in the construction industry. Despite this and the inspections and targeted information campaigns to include the construction industry safety officers still fatalities, and other serious accidents and incidents stops construction workers to work until retirement. Regulations and brochures are used by inspectors in simple and understandable ways explain to users how rules can be applied in their own business to prevent accidents and incidents. For example, there are brochures on the risks related to scaffolding work, roofing, asbestos, etc. During the two in-house training sessions for SWEA's construction inspectors, it was noticed that there was no corresponding material in ergonomics to bring out to the people working on the construction sites. For inspectors felt that it is easier to explain to employers about risks for falling, personal protective equipment, noise and vibration than explaining ergonomics risks. There was also a demand from the construction industry workers for a brochure in which they could recognize themselves in their work in a simple manner by AFS 1998:1 on ergonomics and AFS 2000:1 manual handling. In 2007 the brochure ADI 616 was published.

In the last year SWEA has been commissioned by the government to strengthen information regarding health and safety issues for foreign workers. In many inspections, where inspectors met foreign workers it has been difficult to communicate since there is a lack of knowledge of English or Swedish. This has resulted in difficulties explaining why the inspectors deemed the work unsafe and inappropriate and sometimes has to stop work immediately. As a result SWEA has in autumn 2011 conducted special information campaigns aimed toward foreign workers in Sweden and were carried out on smaller 
construction sites where foreign workers are hired / employed temporarily. For the campaign a brochure produced, ADI 659 Safer building.

At the conference the two leaflets presented (ADI 616 and ADI 659). They are designed to provide information and knowledge about specific risks of occupational accidents and occupational diseases which occur frequently during construction work and how they can be prevented. The target audience is all the persons involved in the construction process at different stages and are subject to SWEAs rules and regulations. SWEAs vision is that everyone wants and can create a good work - also in the construction industry.

\section{Method}

3.1. ADI 616 Ergonomics construction industry prevent the ergonomic risks.

- The text was written by ergonomists and edited an informant. It contains 22 pages of text and one checklist, 16 images and 7 tables of facts.

- The illustrations were developed in consultation with an external illustrator.

- The material was tested by qualitative examination of an external research company. Sample and test panels were randomly selected from the Construction Industry Business Directory. The panel consisted of five employers and three safety officers who voluntarily participated and answered questions if they understood the main message and whether they considered themselves to benefit from the information in the brochure.

- $\quad$ Each person was interviewed for about 20 minutes at a time. A total of eight interviews. They were also asked if they had access to internet and how much they used the internet in the workplace.

- The results of the survey were presented with direct quotations from the interviews.

- The quotes were slightly edited before was submitted for printing.

\subsection{ADI 659 Safer Building}

- Emergency Situations and the basis for the artwork of the brochure was selected and developed in collaboration between the communicator and construction experts within SWEA and market industry-savvy employees in the work.

- The brochure is $13 \mathrm{~mm} \times 78 \mathrm{~mm}$ and twosided. It is designed to be folded in your pocket. It contains a minimum of text to be easily understood even if you do not know the language. Instead you are shown the 13 different situations as 26 images (13 pairs of images). Four of the image pairs illustrate acute musculoskeletal injury risks. In each image pair one image shows the right and the other shows the wrong working method. The wrong method is by an X. The images have been made by an outside illustrator.

- The introductory text of the brochure is printed in eight languages and has been selected on the basis of information from the Migration Board.

\section{Results}

\subsection{ADI 616}

- $\quad 30000$ copies was printed in 2007 and today there are none left in stock. It is planned to press on it in 2012 after a revision made in the text due to change in the legal text of Coordinator for Safety and Health responsibilities.

- $\quad 7365$ downloads from 2008 until Nov 2011 has been made.

- The brochure has not been evaluated externally by issuing the $2008^{\text {th }}$

\subsection{ADI 659}

- 5000 copies were printed. For information about its existence a direct mail was sent to approximately 900 builders / contractors.

- 3,000 copies have been in autumn 2011 over a 6 week period to foreign workers and the employers who hire them. 


\section{Discussion}

Why is it so difficult to spread and get out the message about how to avoid getting hurt or getting unnecessary musculoskeletal disorders? Considering it pays to work safely and everybody really ought to be willing and be able to prevent and minimize the risk of injury. SWEA spent a great effort on both inspection and central supervision. The head office ensures that laws and regulations, brochures and interactive web programs, etc. are made to target the construction companies. The work environment inspectors should have access to the information needed for the dissemination of knowledge. Brochures are available on how to prevent accidents at work on ladders and scaffolding, how to coordinate responsibilities at the site and how to prevent before building. Yet this has not led to large reduction of accidents and injuries among workers. New identified risk groups are e.g. students, apprentices and foreign workers temporarily employed in Sweden. Musculoskeletal disorders continue to be a very large extent because the workers continue lifting and carrying manually instead of using appropriate tools. We also see that there are still work being carried out in narrow installation spaces during contraction of new buildings. This is due to that the drawing responsible persons do not take notice of the need for space necessary to do the work.

To give the industry more knowledge about how to prevent musculoskeletal injuries ADI 616 is the only brochure aimed for the audience with a focus on the ergonomic risks. Prior to issuance of ADI 616 was examined to see if the message was arrived. Several of the quotes about how the language was perceived was positive such as "well written, easily written," "nothing complicated", "it was long from the start, but it was nothing like it was too much on", "I read it pretty carefully and it gave a lot". "It is always difficult to translate it into reality that is the difficult part." "The images were perceived as "good and clear" that "contributed to the understanding and made it easier to absorb the material." Safety representatives felt that the material was written for them but also for their managers. They were willing to order the material to share with their colleagues and their employer. Comments from employers were e.g. the main message "to think before you act" and that "information is useful and relevant to most people. But it also revealed that "often we cannot influence it ourselves without the architects - suddenly, a three meter long window shall be installed." They gave suggestions how to include more information on preventive exercises and figures on what the employer gains by avoiding sick leaved personal so that they become more motivated to invest in good health. The brochure was printed without the changes made. The brochures were distributed via intranet, newsletters and SWEAs building inspectors, to be used in inspections and construction companies networking. The marketing was not in the same way as the ADI 659 which was sent out to especially selected companies immediately after printing. The ADI 659 was more of advertising brochure on the agency's external website. Demand has been spread evenly over the past five years and can still be downloaded from SWEAs website.

The brochure ADI 659 was part of a larger intensive campaign with a website and posters. The method used was traffic advertising at eight different locations in the country, during a six week period in autumn 2011. Mainly on buses, in subway and commuter trains. It has been rapidly spread and with good impact. Promotional information about safer working environment at construction sites will remain in their specific Web site: www.safeatwork.se The information is also available in the Swedish general and industry-targeted media and foreign media, organizations, associations and appropriate sites. This page has a direct link to the brochure as a pdf. The campaign also organized an information film that has already been seen 3000 times in many languages. The website had more than 57,000 visitors during those six weeks. As a result of the campaign's effectiveness to target foreign workers, SWEA decided that the campaign will be extended to the end of the year.

Prior to reprinting ADI 616 as ordering materials, a request should be made to vocational schools, individual entrepreneurs and planners in the construction sector. This in order to secure that it is readable and understandable for them. The proposals that emerged from the study at the eight interviews should also be considered and may be incorporated in the material. SWEA has particularly noticed that there is a reason to highlight that young people more often than adults, have physically demanding job. They are not often involved in determining the pace of work and when and how tasks should be performed. What is needed to make the ADI 616 as interesting and acclaimed as the ADI 659? Do more pictures need to correspond to ADI 659 instead of the amount of text? And is there 
an interest in having ADI 616 translated into several languages? And can E-learning be an attractive way for young people to learn about ergonomics? There are already on SWEAs website interactive training for construction work (in six languages) where musculoskeletal problems are mentioned but not to the extent that the risk of musculoskeletal injuries is clearly apparent. It will also shortly be a general E-learning in ergonomics that can be used in the construction industry to increase the general knowledge of what ergonomics is and what impact it has on health. The campaign for foreign workers clearly showed that it is successful and SWEA should continue to use more of various media such as internet and construction industry of gaming sites, etc. to get the support and knowledge for dissemination of materials (brochures) about how to prevent accidents and injuries and get musculoskeletal disorders to reduce sharply in the construction industry.

\section{References}

[1] Swedish Work Environment Authority. Annual report 2010

[2] Swedish Work Environment Authority. Work-Related Disorders 2010 (2010:4)

[3] Swedish Work Environment Authority. Short work injury facts No. 2 / 2011 Construction. Korta arbetsskadefakta. Nr 2/2011 Byggverksamhet

[4] Swedish Work Environment Authority. (2008). Ergonomics in building and construction. Prevent the risks for musculoskeletal disorders. ADI 616

http://www.av.se/publikationer/broschyrer/adi 616.aspx

[5] Report from Markör

[6] Swedish Work Environment Authority. (2011) Safer building ADI 659

http://www.av.se/publikationer/broschyrer/adi_659.aspx

[7] Swedish Work Environment Authority. Surface for information campaign: Foreign workers in comstruction sector 2011

[8] Swedish Work Environment Authority. Surface for "Safe at work"

[9] Swedish Work Environment Authority. An ergonomic training program for inspectors supervising the building construction industry V. Wiberg and P .Nylén 